\title{
Story Around the Wonderful World of Corals
}

\author{
Aju Mukhopadhyay \\ Poet, Critic and Author \\ India \\ ajum24@gmail.com
}

\begin{abstract}
Corals are special to our lives; they give us when alive as well as on their death. Corals are at the centre of biodiversity. Many solid elements allow us to stand, sit on or sleep on. Earth is the most common but we may rest on sand hill, mountain top or tree. Corals provide us the same solid base to stand on as earth when it dies. When it lives it gives shelter, protection and food to many living things. Coral reefs offer multiple benefits to people and the economy - providing food, sustaining livelihoods, supporting tourism, protecting coasts, and even helping to prevent diseases. India has many coral coasts and coral areas.

Lakshadweep is the largest among them. The coral reef in and around Lakshadweep has fascinated us. A travel in the remote islands and visit among the corals was an unique experience. The article deals with all aspects of coral kingdom including the islands. Not only facts and figures, it tells the story of travel and more; what happened on the way and in between; adventurous from the beginning to the end.

Keywords: Coral Reef, Biodiversity, Kayaking, Livelihood, Tourism

Before we share the joy and adventure of our travel in the coral world we feel it a duty to let you know about the geographical feature of the whole area called Lakshadweep.
\end{abstract}


Lakshadweep is an archipelago of 12 atolls, three reefs and five submerged banks. There are 36 islands covering an area of $32 \mathrm{sq} . \mathrm{km}$; each ranging from 0.1 to 4.9 sq. $\mathrm{km}$. Only ten islands are inhabited. They remain scattered in Arabian Sea at a distance of 225 to $445 \mathrm{~km}$ from the Kerala coast. Kavaratti is the capital of this smallest Union Territory of India

\title{
Travelling around Lakshadweep
}

\author{
residents of the land- \\ wonderment waits for you \\ in water
}

Towards the evening while sailing in a ship in the ocean vast and deep some strange sights attracted us. Suddenly some bird like animals started flying above the surface water emerging from below the depth and after flying some distance fell on the water again to be sunk in it. Did some of them fly over the sky? Flying fishes dazzling like silver sheets in the dying rays of the sun increased our attention and curiosity. Strange but a fun to observe.

They were the

Butterfly fishes (Chaetodon Trifasciatus). They couldn't have flown over the sky, a scientist observed.

$$
\begin{aligned}
& \text { midnight dark } \\
& \text { engulfed us- } \\
& \text { starlit dream }
\end{aligned}
$$

After a fast meal and short nap we gathered at the beach and beheld what we could not view perfectly while coming as we were quite tired and hungry then; the colours of the sea. They seem different while in the middle of the ocean from viewing from the shore. It is perhaps Lakshadweep and such rare areas on earth like Maldives and Seychelles islands that offer 
the greatest occasions for feasting the eyes on the colours of the sea. Here it is turquoise there aquamarine, still farther as one looks it is sapphire and amethyst, almost touching the blue of the sky. The water soon becomes greenish yellow and yonder it is blue-black again. The sand below our feet, actually the pounded coral reef, is softer than usual sand; very soothing. colour splashed over the sky and sea- looking at each other

The water of the sea, somewhere transparent somewhere opaque according to the depth, invited us for kayaking. One of the colourful fiberglass boats with oars and life jackets, available aplenty on the shore, was taken for a ride by two of us for kayaking around the jetty and sometimes beyond. It was a fun and pleasure to kayak, to splash water on each other while passing alongside the swimming big-bodied hawksbill turtles as our companions. Travelling in the clear lagoon water in an open glass-boat we found an wondrous world of marine wealth opened before us; coral reefs, polyps, multicoloured fishes with colourful fins and gills, slippery lichens, anemones, sea cucumbers, green and hawksbill turtles, eels, squids, star fishes, butterfly fishes, different angel fishes including the beauteous emperor angel fishes with white circles on semi round black bodies and innumerable insects and other living and non-living things. I couldn't list all the colourful denizens of the Lakshadweep lagoon, hiding and playing with protruding eyes but sure that it was a complete biodiversity, a compact living world with vegetarians and non-vegetarians beyond our day to day earthly experience. One of them, the big hawksbill turtle swam alongside the shore. It is a native of Lakshadweep, a huge animal like the Green turtle.

We saw many of them along with many coloured beauties; swimming, crawling or playing while travelling to Bangaram and Tinnakara islands. Our travel around and up to Bangaram was somehow risky and adventure in almost frail motorboat rocking and swaying against the violent waves splashing water inside, sometimes drenching sometimes making us breathless. 
As we came back the risky journey remained with us; an unforgettable experience.



Suhali and Tinnakara are among the largest nesting beaches among many inhabited and uninhabited islands of the region. Green and hawksbill sea turtles abound here But Tetra pods cordoning the islands restrict nesting and hatching of sea turtles, leading towards their decline.

It is their home; we are intruders.

Pitti island with choppy waves and rugged rocky surface is a haven for different types of birds like Terns (sterna) and Lesser Noddy (anous tenuirostris) besides others. Turbulent sea and rocky shore threatens landing on it but it is an adventurous delight for the birders. The islands here are made of the body of the coral reefs formed by corals. Their body secretions, skeletal remains and chemical compositions on the shallow water create lagoons.

$$
\begin{aligned}
& \text { they live to give food } \\
& \text { and shelter create space } \\
& \text { at death }
\end{aligned}
$$

\section{Spawning and Spilling}

Coral spawning is a magnificent phenomenon in the seas after the full moon nights. Corals release male and female spawns and together they form the larvae. It's a mass collective expulsion of colourful eggs and sperm clouds into the water by corals; a result of coral sex. It is a usual annual occurrence. During spawning the eggs are fertilised and form 
larvae. The larvae then float off till they find suitable substrates to settle and form their own colonies; thus corals thrive. The gametes then rise to the surface of the ocean creating a colourful slick. survey shows that the larvae forms slick-like layers around four islands; Agatti, Bangaram, Thinnakara, and Kavarrati. Some locals when questioned regarding the phenomenon said they had presumed it to be oil spills.

This finding in 2013 at Lakshadweep proved, as the scientists observed, that Lakshadweep's corals are recovering from the stress they experienced after El Niño, 2010. One Dr B C Choudhury, a senior advisor for WTI, was elated with the news. "This comes at a time when a lot of pessimism surrounds the state of our corals - with talk of them getting bleached, their habitats being destroyed, global warming, sea levels rising and so on. It is really a magnificent sight, and the team of scientists at Lakshadweep was really fortunate to witness it. It should give impetus to others working with corals to look out for their seasons of spawning and encourage people to monitor these beautiful organisms on a larger scale." 1 Spawning normally happens when the water is warm, and when the tide is changing from high to low.

"Different species spawn at different times and follow different patterns," said Dr Choudhury, "Much more research needs to be done to understand the process clearly." 2 Dr Alasdair Edwards, professor at Newcastle University, UK, said that while it has been spotted much earlier than expected, "We expect corals to spawn a week after full moon nights in March . . or April ...” he said, "This event also shows that corals spawn in day as well, though not as common as at night." 3

Coral spawning is a big tourist attraction in the Great Barrier Reef in Australia, where it generally happens soon after the full moon in November or December. In the Maldives, spawning has been scientifically determined to take place between the end of January and the 
beginning of March. But there is no universal date of spawning anywhere. It was first recorded in 1981.

\section{Born to die they thrive in the lap by the Corals}

Many more are the fishes and other aquatic animals that live around coral islands and reefs in different parts of the globe but the following, though common in other areas also, are particularly present in Lakshadweep.

each is different from the other-

$$
\text { biodiversity }
$$

\section{Gentle Green Turtle (Chelonia mydas)}

Green sea turtles are confined to the warm tropical waters of both the hemispheres. It is available in the entire east and west coast. Lakshadweep is their main nestling ground. It grows over a metre in length and weighs up to $155 \mathrm{~kg}$.

\section{Colourful Blue Sea Star (Linckia laevigata)}

This elegant sea fish is available in shallow lagoon waters. It is abundant in Minicoy and Kalpeni islands, parts of Lakshsdweep. Besides blue it has brown, light blue and red colours also in some species.

\section{Redfin Butterfly fish (chaetodon trifasciatus) can swim and fly}

Redfin is the most common Butterfly fish. It can be seen in small aggregations feeding on coral polyps. The disc-like shape and extraordinary colours make them the most sought after aquarium fishes. 


\section{Beautiful Emperor Angelfish (Pomacanthus imperator-juvenile)}

Emperor is a beautiful member of the angelfish family. It is seen single and in pairs in territorial sea and lagoons. The adult is not as shy as the juvenile in allowing proximity. It grows up to $40 \mathrm{~cm}$ feeding mostly on algal matter, tunicates and sponges.

\section{Squids Hide}

They have internal shells. Fast moving, it usually lives in deeper water but can be seen in shallow water of the reefs during breeding season. It usually camouflages; difficult to identify unless seen from a close quarter.

\section{Subtle and Effective Christmas-tree worm (Spirobranchus giganteus)}

The tentacles of the worm look like Christmas tree. These are used to capture food. It is very sensitive to shadows and vibrations. Threatened, it pulls back itself into its tube and closes a 'trap door' over the top. A close relative of the earth worm, it can bore into massive corals like

Porites Lutea.

\section{Better Avoid Bubble Anemone (entacmae quadricolor)}

Anemones are relatives of the corals but differ in structure and behaviour. A special disc at the bottom helps anemone to attach itself to the substrate. But it can move slowly over rocks and corals. Tentacles of the sea anemone have nematocysts which warn a contact with it. Bubble anemone is a beautiful large sea anemone. Its tentacles are transparent and bulbous at the tips.

It usually occurs in shallow lagoon water. 


\section{Stonefish (Synancela verrucosa): most dangerous on earth}

With an ugly looks and shape it is the most venomous of fishes in the world. It is very common in reef flats. It grows up to $35 \mathrm{~cm}$. Its dorsal fin contains venomous neurotoxin.

Coming in contact with this fish may endanger human life. It is best to avoid its contact.

\section{Harmless Whitetip Reef Shark (Triaenodon obesus)}

Smaller than Tiger or Grey Reef shark $(225 \mathrm{~cm})$, found in the deeper reef slope around Lakshadweep, it is most harmless. With interest and care one may enjoy its grace and swift movements in the sea. Large scale killing of pelagic sharks for fins is a danger to its conservation.

\section{Don't provoke Black-blotched Moray Eel (Gymnothorax permistus)}

Usually found sticking out its head from a cave or ledge, elegant looking, it grows up to $70 \mathrm{~cm}$. It looks dangerous as it constantly pumps in water through the mouth and throws it out from small opening at the side of its neck as it requires and draws oxygen like fishes. Usually harmless it may attack if provoked. Powerful jaws of eels can rip apart chunk of flesh.

\section{Endangered Giant Clams symbolise coral reef health but endangers other's health if}

\section{touched}

Most clams except giant clam, oyster and mussels burrow into sand and feed on filter. Many of them are favourites of children. Giant clams are special in many ways. They have mesmerized people with their fluorescent mantle. They grow up to one metre. Though not as big as cat, they play an important role in reef ecosystem. Mostly living for more than 
100 years they remain symbol of coral reef health. They occupy a specific niche in coral reef.

They avoid places near wave break or sea beds to a void risk of wave actions. Plankton feeders (microscopic animals and plants by filter feeding). Giant clams are bivalve (two valves joined by a hinge) Phylum Molluscs, boneless and soft bodied, usually found in the shallow water of the reef in tropical seas.

They have the ability to cultivate plant in their body tissue (Zooxanthellac, an unicellular algae). This is an unusual phenomenon of endosymbiosis (one symbiotic organism living inside another). Some other species have this capacity but giant clams are unique in a way that they cultivate zooxanthellac in a special circulatory system. They are special in their fluorescent and very colourful mantle which make them more attractive victims of international trade. Like most molluscs they are simultaneous hermaphrodites, having both male and female organs producing both sperms and eggs and thus capable of selffertilization.

But this being contrary to Nature's way they have adopted to synchronization of releasing sperms simultaneously with other clams releasing eggs. This is done on open sea and the resultant floating larvae seek shelter in any substrate. Against the high mortality of larvae giant clams produce huge number of eggs and sperms; 500 million per animal. This animal has powerful abductor muscle with strong valves which may cause damage if someone touches or goes near it. Of the ten species of giant calms four occur in India. Giant clams and juvenile clams are demanded as delicacies at some places. In China clam's abductor muscle is considered aphrodisiac, its medicinal value calls for demand from some other quarters, even their shells are traded. Threats are from some predators also. Loss of coral reef entails loss of habitat for giant clams also. The Giant Clams Project of Bombay Natural 
History

Society since 2004 has been a success with the cooperation of the local people.

\section{Autonomous soft bodied Sea Slugs are armed with weapons}

Opisthobranchs or sea slug has been defined in the dictionary as any of a subclass of Opisthobranchia; a marine gastropod mollusc that have the gills when present posterior to the heart but often lack a shell.

They are soft bodied, highly colourful and diversified molluscs. They have a variety of colourful body ornamentation like flaps, tubercles and tentacles. They occur in most marine ecosystems from warm tropical to cold temperate waters. Their diversity is highest in tropical waters. Of the total 6000 varieties of sea slugs 400 are present in India and BNHS by research has found another 150 species of such animals in India. Some of the species are wide spread and some are restricted in their movement. They are mostly carnivorous and nocturnal.

Usually found in pairs but large congregations of opisthobranchs are not uncommon. Smallest sea slug, Siphopteron ligrinum, found in India, measures up to $3 \mathrm{~mm}$ but the largest, Hexabranchus sanguineus, grows up to $550 \mathrm{~mm}$. Without shell and soft body, colourfully attractive, sea slugs have developed some self defense system as evolved in nature, such as autonomy (casting off body parts), release of ink clouds, chemical secretion, display of body colour and threat posture, using acids, toxins and stinging cells acquired from foods taken. Most interesting is their host specific association. Some species spend their lives in hydroid and some in sponges, some are found in marine algae and some are associates of bryozoans. 


\section{And she was lost to come back}

Among such dangerous and harmless, small and big unforeseen strange animals she was lost while swimming near a remote island we riskily landed in a broken boat. I'm not an expert in sea swimming so I refused to enter into such sea and wished to stop her from venturing into the unknown water. But her obstinate insistence, maddening love and addiction for sea swimming fetched my reluctant and fearful permission. No human was there around. Nothing was seen but we knew that the water has a world of animals and other things like living trees, plants and planks; innumerable, innumerable. She jumped into it and started swimming. With a foreboding I was trying to see that she does not go out of reach but as it often happens with her, enamored of the sea she went far and disappeared from my views. My shouts didn't reach her. Once or twice she reappeared like any other sea animal from below the surface and again drove deep into it swimming untiringly. Oh, how much I shouted as I saw her from moment to moment but she was in it and with it in love and ecstasy.

And she was lost. I could not see her for long twenty minutes. There was none else to counsel or give me solace. No physical help was considered feasible. Tears in eyes, undecided I stood the ground. Alone. Another twenty minutes passed. I could not sit nor move. At last at a distance like the arrival of an angel in dream I saw her coming but not swimming. She was on the back of a Green turtle or hawksbill turtle, I could not make sure. She came laughing, wiping her body with a towel, alighting from the huge body of the happy turtle which came to the shore and dropping her almost vanished. And then what happened would suit a melodramatic chapter of a drama. Let's not go into it again. 


\section{Threat to the Coral World and possible Remedies}

Two types of threats and attacks are usually responsible for the decaying health of coral reefs not only in Lakshadweep but across the tropical belt of the world. Natural disturbances are hurricane, current like El-Nino, coral bleaching, disease of the corals, sedimentation, hyper and hypothetic stress and such other acts of Nature but anthropogenic trouble arise out of human activities like destructive fishing, anchoring and grounding by ships in the coral belt, pollution, nutrient loading, harvesting of reef vertebrates, coral mining and trampling of the reef by tourists and others. These threats to coral life can be minimised by effective environmental management and reduction of anthropogenic behaviour.

Apart from the above the greatest threat to the reefs are from Climate change due to global warming. It was estimated in 2008 that a rise of the sea level by one per cent would cause land loss to certain islands at Lakshadweep like Kiltan, Kavaratti, Kadamat, Kalpeni Cheriyam and Agatti-Banagram to the extent of 11 to 21 per cent thereby increasing the density of population.

World Resources Institute's 'Reefs at Risk' project has produced a series of global and regional map-based reports beginning in 1998: A Map-Based Indicator of Threats to the World's Coral Reefs. The most recent global report, 'Reefs at Risk Revisited (2011)' is a high-resolution update of the first report. 'Reefs at Risk Revisited' is a project of the World Resources Institute (WRI), developed and implemented in close collaboration with The Nature Conservancy (TNC), the World Fish Center, the International Coral Reef Action Network (ICRAN), the United Nations Environment Programme - World Conservation Monitoring Centre (UNEP-WCMC), and the Global Coral Reef Monitoring Network (GCRMN). Many other government agencies, international organizations, research 
institutions, universities and nongovernmental organizations provided scientific guidance, contributed data, and reviewed results. According to this report:

Seventy-five percent of the world's coral reefs are currently threatened by local and global pressures. For the first time, the analysis includes threats from climate change, including warming seas and rising ocean acidification. The most immediate and direct threats arise from local sources, which currently threaten more than $60 \%$ of coral reefs. Local threats include impacts from fishing, coastal development and pollution. Left unchecked, the percentage of threatened reefs will increase to more than $90 \%$ by 2030 and to nearly to hundred per cent by 2050 . For the first time, the report identifies 27 nations most socially and economically vulnerable to coral reef degradation and loss. Among these nine most vulnerable countries are: Haiti, Grenada, Philippines, Comoros, Vanuatu, Tanzania, Kiribati,

Fiji, and Indonesia. 4

Latest studies corroborate with the above views in the report but tells us about the development thereafter.

Actual harms were estimated to be lesser than this projection because of the absence of effects transmitted from and amplified by the neighbouring terrestrial environments. Reefs are usually beyond the reach of the human population so the anthropogenic threat is diminished. It was observed at Wild Life Trust of India in 1913 that the reefs recovered from the stress and strain to a good extent. It was also reported by Bombay Natural History Society which launched 'Project Giant Clam' in 2004 in collaboration with LEAD and financial support from Darwin Institute, UK. In collaboration with the local community Agatti Conservation was a successful endeavour. Local population cooperated in the development of the islands under the scheme of Marine Protected Areas. BNHS (Bombay Natural History Society) has a long standing Research Station at Lakshadweep. 
In order to protect marine biodiversity, it has been opined that 20-30 per cent of the seas must be under protection but up to 2009 it was only up to one per cent. To achieve this IUCN (International Union for Conservation of Nature) and other influential organisations called for a global network of Marine Protected Areas by 2012. It is an area of intertidal and subtidal terrain together with its overlaying water and associated flora, fauna, historical and cultural features which have been reserved under any Law for effective means to protect all or part of the enclosed environment. With awareness and cooperation of the local community everywhere it is receiving effective impetus towards progress.

\section{Concluding views about the Coral World}

Many solid elements allow us to stand, sit on or sleep. Earth is the most common but we may rest on sand hill, mountain top or tree. Corals provide us the same solid base to stand on as earth when it dies. When it lives it gives shelter, protection and food to many living things.

Corals are at the centre of biodiversity. Coral reefs offer multiple benefits to people and the economy - providing food, sustaining livelihoods, supporting tourism, protecting coasts, even helping to prevent disease. According the report more than 275 million people live in the direct vicinity $(30 \mathrm{~km} / 18$ miles $)$ of coral reefs. In more than 100 countries and territories, coral reefs protect 150,000 km (over 93,000 miles) of shorelines, helping defend coastal communities and infrastructure against storms and erosion.

Corals are wonderful creation by Nature; creatures creating wonder world in oceans extended to earth. Around the coral reefs and beyond there are many famous and infamous animals in the womb of brine water like dugong, dolphin, crocodile, gharial, hippopotamus, whale and innumerable fishes. 


\section{a world in}

itself under the

sky- it invites

If we realise the benefit we derive by the coral world we should make all out efforts to preserve it by eliminating its risk to the extent possible and helping it to grow up to its infinite limits. 


\section{Notes and References}

Wildlife Trust of India; 26.3.2013

Wildlife Trust of India; 26.3.2013 Wildlife

Trust of India; 26.3.2013

Internet links:

https://www.google.co.in/search?q="Reefs+at+Risk+Revisited\%2C"+released+by+world+

Resource+Institute\&oq="Reefs+at+Risk+Revisited\%2C"+released+by+world+Reso urce+Institute \&aqs=chrome.

http://pdf.wri.org/reefs_at_risk_revisited.pd

https://oceanservice.noaa.gov/news/weeklynews/feb11/reefs-at-risk.html 